\title{
Fabrication and Evaluation of Gemcitabine-loaded Alginate Microspheres: A Potential Approach for Treatment of Various Carcinomas
}

\author{
Maruf Hossain', Shayeri Chatterjee ${ }^{1,2, \star}$, Hiranmoy Paria ${ }^{1}$, Soumya Ganguly ${ }^{1}$ \\ ${ }^{1}$ Department of Pharmaceutics, Calcutta Institute of Pharmaceutical Technology and Allied Health Sciences, West Bengal, INDIA. \\ ${ }^{2}$ Department of Pharmacy, Techno India University, West Bengal, INDIA.
}

\begin{abstract}
Aim/background: Microspheres are spherical particles, having a core, having a particle size of $1 \mu \mathrm{m}$ to $1000 \mu \mathrm{m}$. They are advantageous as compared to conventional dosage forms of drugs, in parameters like sustainability and control of drug release, drug protection, biodegradability, targeting ability and many more. Gemcitabine is a prodrug and is used in various carcinomas. Sodium Alginate and Ethyl Cellulose are used as polymers. The fabrication aims to sustain the drug release which can treat pancreatic, breast, ovarian and lung cancer. Materials and Methods: Microspheres have been made by lonotropic Gelation method, Sodium alginate, Ethyl cellulose and Calcium chloride. Weighed quantity of drug and polymer were added to sodium alginate solution, which was then added drop wise to Calcium chloride solution under continuous stirring to procure spherical rigid microspheres. These were then subjected to various physicochemical characterizations and surface analysis. Results and Conclusion: Results have shown that by increasing the polymer concentration, entrapment efficiency and drug loading have also increased. Particle size, SEM and micromeritic evaluation have exhibited satisfactory results. The drug release studies depict that most of the batches have showed less than $10 \%$ release acid media so it protects the drug from the upper part of GI Tract. These attributes prove that microsphere technology, being a crucial novel drug delivery system can be very effective in reducing dose frequency, dose dumping and better patient compliance.
\end{abstract}

Key words: Gelation, Targeting, Sustainability, Microspheres, Entrapment Efficiency.

\section{INTRODUCTION}

Conveyance of oral drugs had become a widely acknowledged route of administration of therapeutic drugs, yet the susceptible drugs undergo degradation in the small intestine by gastric juice and enzymes due to several formidable hindrances from gastro-intestinal tract. Attributable to various benefits of the microspheres, it has been widely employed in augmenting the duration of drug action, safeguarding the drug in the core and targeting the drug in the desired site as well.

Malignancy is one of the paramount causes of morbidity and mortality worldwide. Hence, the concept and application of encapsulated drug delivery, to treat these types of site-specific disorders have created immense interest in the fields of medicine and research. Intravesical delivery of chemotherapeutic drug candidates cater to that efficacious drug localization to the target site, reducing toxicity and bypassing unnecessary damage to the other healthy tissues. The application of drug loaded microspheres in treatment of various carcinomas have been quite promising. Gemcitabine hydrochloride (Gem-HCl; $2^{\prime}, 2^{\prime}$-difluorodeoxycytidine) is a water-soluble pyrimidine analogue with a wide range of antitumor activity. ${ }^{1,2}$ It is transported into the cell, phosphorylated, and incorporated into DNA and RNA, which causes impediment
Submission Date: 18-04-2021; Revision Date: 17-07-2021; Accepted Date: 15-10-2021.

DOI: 10.5530/ijper.56.1.11 Correspondence: Mrs. Shayeri Chatterjee, Assistant Professor, Department of Pharmaceutics, Calcutta Institute of Pharmaceutical Technology and Allied Health Sciences, Howrah-711316, West Bengal, INDIA. E-mail: shayeri.ch1992@ gmail.com

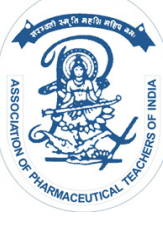

www.ijper.org 
of growth activity and moderates apoptosis. ${ }^{3}$ For showing the pharmacological activity inside the body it has to be phosphorylated into its active metabolite, gemcitabine triphosphate and diphosphate, which happens by the action of deoxycytidine kinase in the body. These active metabolites get incorporated into the DNA strand and inhibit the DNA synthesis thereby inhibiting cell growth. Currently the drug is accessible for parenteral administration but is rapidly metabolized as it is widely deaminated by cytidine deaminase in blood and other organs. ${ }^{4}$ This causes the dosage frequency to be increased to get the therapeutic concentration for a longer duration which thereby aggravates the total amount of GEM to be administered during the therapy of cancer.

Hence there is a need to develop a delivery system which not only increases its stability but also has a sustained release of Gemcitabine for a longer duration. It has been reported that novel drug delivery systems like nanoparticles or microparticles would not only provide efficient delivery of the anticancer drug like Gemcitabine to the cancer cells but also protect the drug from rapid metabolization. Gemcitabine has been adopted as a preliminary line of therapy, alone for pancreatic carcinoma, and simultaneously with Cisplatin for treating progressive metastatic bladder malignancy just as metastatic non-small cell lung carcinoma. It has also been employed as a second-line of treatment, conjointly with Carboplatin, for ovarian carcinoma and thatwithPaclitaxelformendingmetastaticcarcinomas of pancreas. ${ }^{5}$ Sodium alginate and ethyl cellulose have been implemented as polymers ${ }^{6}$ in this study, in order to provide an enhanced residence time and intimate contact with the absorbing surface. Nine batches of microspheres have been formulated by ionotropic gelation technique, ${ }^{7}$ aiming to maintain the intactness of the drug throughout the gastric environment and make it degrade in the colon.

\section{MATERIALS AND METHODS \\ Materials}

Gemcitabine Hydrochloride has been purchased from TCI chemical India Pvt. Itd. Sodium Alginate and Calcium Chloride have been purchased from Merck life Science Pvt. 1td. Ethyl cellulose was procured from Loba chemicals.

\section{Methodology}

\section{Preparation of Calibration Curve of Gemcitabine Hydrochloride}

Calibration is done $e^{8}$ in phosphate buffer $\mathrm{pH} 6.8$ and in acid buffer $\mathrm{pH} 1.2$ respectively. Aliquots of stock solution $(1000 \mathrm{mcg} / \mathrm{ml})$ was suitably diluted with $\mathrm{pH} 6.8$ phosphate buffer to give final concentrations of 5,10 , $15,20,25,30$ and $100 \mathrm{mcg} / \mathrm{ml} .10 \mathrm{ml}$ of the stock solution was diluted with $0.1 \mathrm{~N}$ Hydrochloric acid to give a standard solution, having a concentration of $100 \mathrm{mcg} / \mathrm{ml}$. Standard curves were plotted likewise.

\section{Drug-Polymer Interaction Studies}

The IR spectra procured from FT-IR spectrophotometer, ${ }^{9}$ utilizing $\mathrm{KBr}$ pellet technique, in the wavelength region between $600-4000 \mathrm{~cm}^{-1}$ for Gemcitabine Hydrochloride and its blend with polymers were compared to estimate the compatibility, ${ }^{10}$ of drug with polymers. The thermograms of samples, ${ }^{11}$ was acquired at a scanning rate of $10^{\circ} \mathrm{C} / \mathrm{min}$ over a range of 50 to $350^{\circ} \mathrm{C}$ temperature.

\section{Preparation of Gemcitabine Hydrochloride Microsphere}

This was carried out by implementing ionotropic gelation technique. ${ }^{12}$ Required quantity of drug and polymer were given to $100 \mathrm{ml}$ of solution, loaded with Sodium alginate and agitated at around $300 \mathrm{rpm}$. Consequently the solution dispersion was added through a needle of 21 gauge, drop by drop to a $100 \mathrm{ml}$ of solution containing Calcium chloride, under uninterrupted stirring, which was proceeded for $30 \mathrm{~min}$ to complete the reaction, ${ }^{13}$ for procurement of spherical rigid microsphere. The obtained microspheres were subjected to filtration and washing with purified water and then drying at $40^{\circ} \mathrm{C}$ for $6 \mathrm{hr}$. The dried microspheres were sifted through mesh 30 . Table 1 depicts the fabrication of microspheres.

\section{Evaluation of prepared microspheres}

\section{Micromeritic properties}

Micromeritic properties ${ }^{14}$ were estimated, which includes bulk denity, tapped density, carr's index, angle of repose and Hausner's ratio. Particle size was analysed ${ }^{15}$ was by taking the microsphere containing slide, placed on the microscope and diameter of 100 particles was assessed using a calibrated optical micrometer.

\section{Drug entrapment efficiency, Drug loading and Percentage of yield}

$100 \mathrm{mg}$ of the microsphere was taken to a $25 \mathrm{ml}$ of a solvent system that comprises of methanol and $0.1 \mathrm{~N}$ Hydrochloric acid, in the ratio of $2: 1$ at room temperature for $24 \mathrm{hr}$. This solution was filtered, ${ }^{16}$ and the filtrate was examined spectrophotometrically for content of drug at $268 \mathrm{~nm}$.

Drug loading in $\%=\mathrm{W} / \mathrm{W}_{\mathrm{t}} \times 100 \quad$ Equation 1

Entrapment Efficiency in $\%=\mathrm{W}_{\mathrm{c}} / \mathrm{W}_{\mathrm{o}} \times 100$ Equation 2 


\begin{tabular}{|c|c|c|c|c|}
\hline \multirow{2}{*}{ 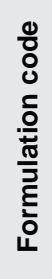 } & \multirow{2}{*}{ 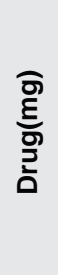 } & 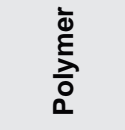 & $\frac{\grave{\Sigma}}{\bar{\partial}}$ & \multirow{2}{*}{ ह } \\
\hline & & 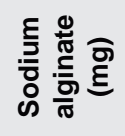 & 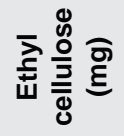 & \\
\hline F1 & 50 & 350 & 25 & 6 \\
\hline F2 & 50 & 400 & 25 & 6 \\
\hline F3 & 50 & 450 & 25 & 6 \\
\hline F4 & 50 & 350 & 50 & 6 \\
\hline F5 & 50 & 400 & 50 & 6 \\
\hline F6 & 50 & 450 & 50 & 6 \\
\hline F7 & 50 & 350 & 100 & 6 \\
\hline F8 & 50 & 400 & 100 & 6 \\
\hline F9 & 50 & 450 & 100 & 6 \\
\hline
\end{tabular}

Yield $(\%)=$ [weight of microsphere /total expected weight of drug and polymer] $\times 100$

Where, W=Drug content of the microspheres, $\mathrm{W}_{\mathrm{t}}=$ Weight of the microspheres, $\mathrm{W}_{c}=$ Total drug present in the microsphere batch, $\mathrm{W}_{\mathrm{o}}=$ Theoritical drug loading.

\section{In-vitro drug release studies}

It was carried out, ${ }^{17}$ in phosphate buffer $(900 \mathrm{ml}$, having $\mathrm{pH}$ 6.8) maintained in $37^{\circ} \mathrm{C}$ at $75 \mathrm{rpm}$, utilizing USP basket type dissolution test apparatus under sink conditions, by taking $100 \mathrm{mg}$ equivalent drug microsphere into the dissolution medium and $5 \mathrm{ml}$ aliquots were withdrawn and analysed spectrophotometrically at $268 \mathrm{~nm}$.

\section{Surface Topography (SEM)}

The surface morphology ${ }^{18}$ and internal texture of gemcitabine hydrochloride micro particles were observed by scanning electron microscope at $3 \mathrm{~K}$ magnification.

\section{Swellability Studies}

$100 \mathrm{mg}$ of microspheres were put in somewhat abundance measure of distilled water, $0.1 \mathrm{~N} \mathrm{HCl}$ and phosphate buffer ( $\mathrm{pH}$ 6.8) and permitted to expand to steady weight. ${ }^{19}$ The change in weights after 30 min were noted. The degree of swelling (a) was consequently assessed from the formula:

$\mathrm{a}=\mathrm{W}_{\mathrm{g}}-\mathrm{W}_{\mathrm{d}}$ wo; where, $\mathrm{W}_{\mathrm{o}}$ is the weight if the beads and $\mathrm{Wg}$ is the weight of the beads at equilibrium swelling in the medium.

\section{RESULTS AND DISCUSSION}

The standard calibration curves were calculated at 200 to $800 \mathrm{~nm}$ and wave length $\lambda_{\text {max }}=268 \mathrm{~nm}$ phosphate buffer (pH-6.8) and $0.1 \mathrm{~N} \mathrm{HCl}(\mathrm{pH}-1.2)$ and the standard calibration curve for gemcitabine hydrochloride with regression value of $0.9927,0.9935$ respectively are shown in Tables 2, 3 and Figures 1, 2 respectively.

$\begin{gathered}\text { Table 2: Spectrophotometric data for estimation of } \\
\text { Gemcitabine hydrochloride in Phosphate buffer } \\
\text { (pH-6.8). }\end{gathered}$
\begin{tabular}{c|c|c|} 
SI. No & Concentration $(\mu \mathrm{g} / \mathrm{ml})$ & Absorbance \\
\hline 1 & 5 & 0.101 \\
\hline 2 & 10 & 0.288 \\
\hline 3 & 15 & 0.584 \\
\hline 4 & 20 & 0.777 \\
\hline 5 & 25 & 0.951 \\
\hline 6 & 30 & 1.136 \\
\hline
\end{tabular}

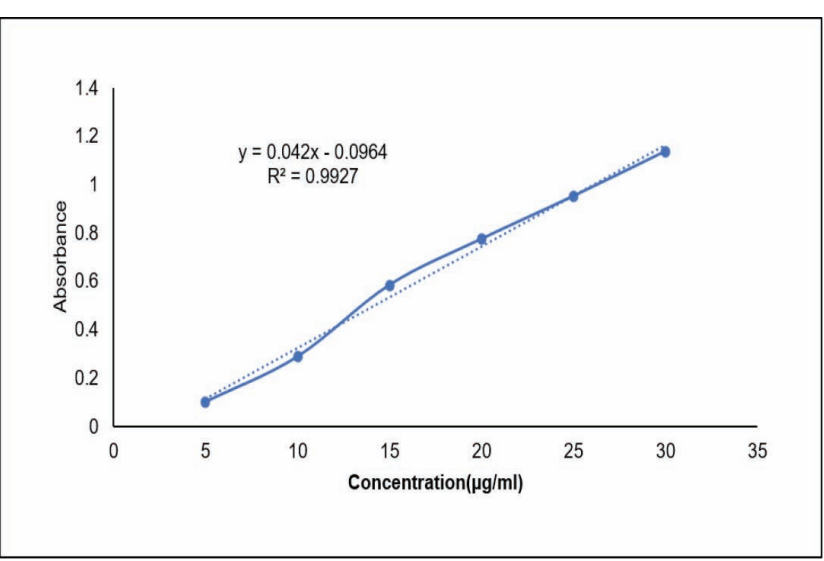

Figure 1: Standard curve of Gemcitabine Hydrochloride in Phosphate Buffer (pH 6.8).

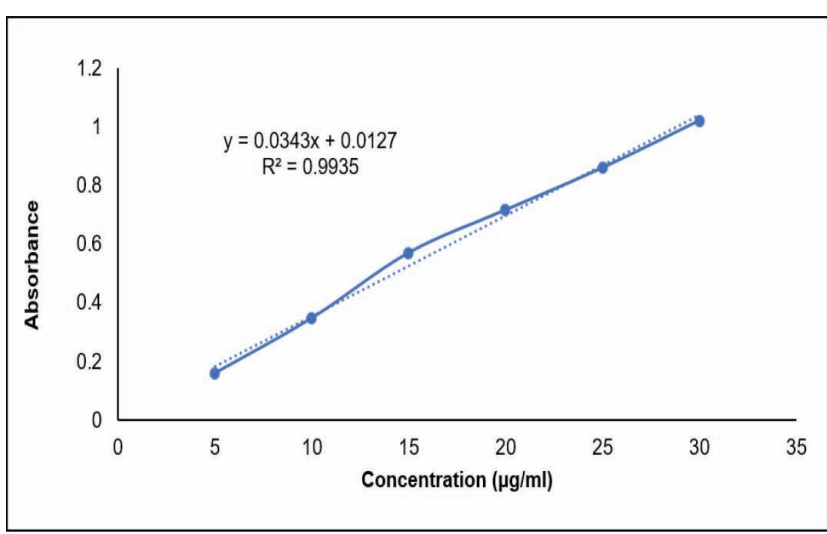

Figure 2: Standard curve of Gemcitabine Hydrochloride in $0.1 \mathrm{~N} \mathrm{HCl}(\mathrm{pH}-1.2)$. 
Fourier Transform Infra-Red Spectroscopy (FT-IR Analysis)

The supplied sample was identified by FT-IR spectrum which is concordant with the reference spectrum of Gemcitabine Hydrochloride, as shown in Figure 3. It complies with official compendium, exhibiting that there is no significant reaction between the drug and the polymer.

\section{Differential Scanning Calorimetry (DSC)}

From the results of DSC Thermogram, as shown in Figure 4, it can be concluded that the melting point of the sample is in concordance with the pure drug, as per official compendium.

\section{Drug Loading and Drug Entrapment Efficiency}

The results of drug loading increased from $2.30 \pm 0.058$ $\%$ to $13.56 \pm 0.082 \%$ of microsphere with increasing

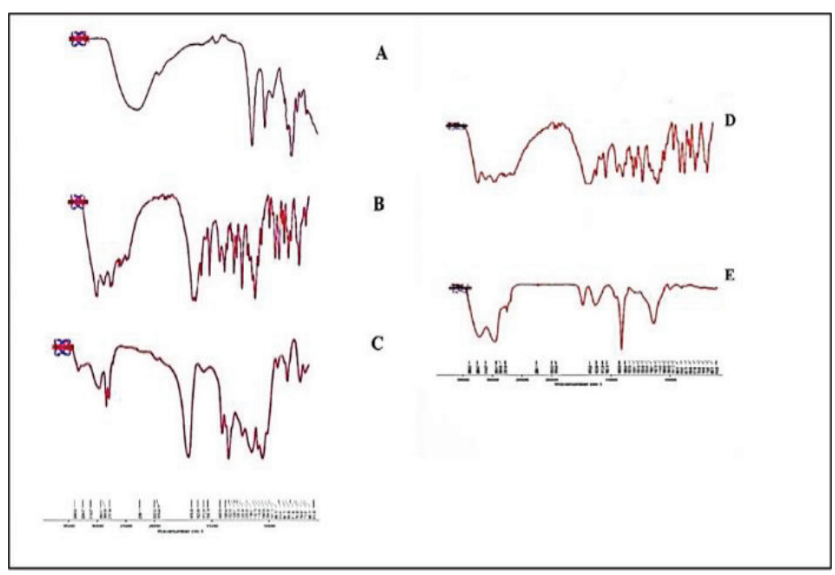

Figure 3: FTIR of Sodium Alginate (A), Ethyl Cellulose (B), Physical Mixture (C), Gemcitabine. Hydrochloride Pure Drug (D), Microsphere Formulation F8 (E).

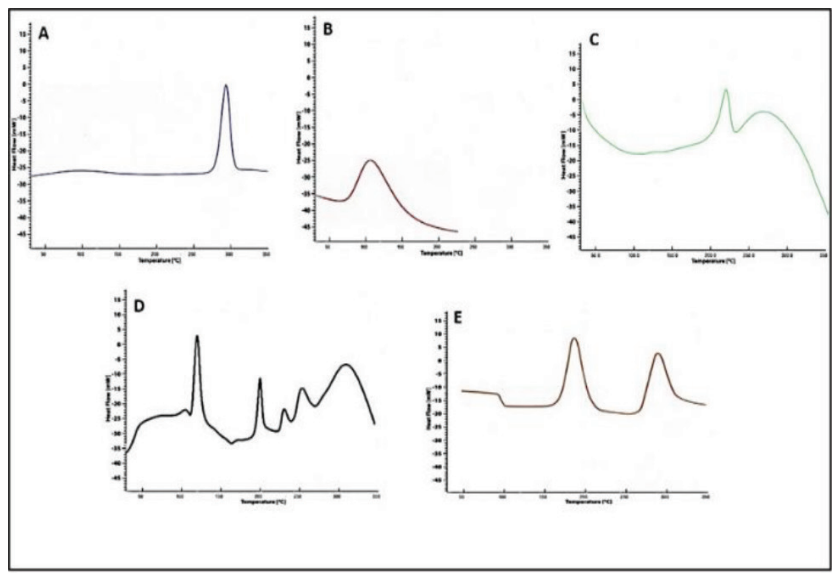

Figure 4: DSC Study of- A) Pure Gemcitabine Hydrochloride B) Sodium Alginate C) DSC Study of Ethyl Cellulose D) DSC Study of Physical Mixture E) DSC of Microsphere F8. amount of polymer, as shown in Table 4, Figures 5 and 6 respectively. The percentage encapsulation efficiency was increased up to $13.69 \pm 0.025 \%$ to $79.09 \pm 0.096 \%$ with increasing polymer concentration of ethyl cellulose.

\section{Particle size Analysis and Surface Morphology}

Particle size has been determined by sieve analysis method. The mean diameter of microsphere decreases

\section{Table 3: Spectrophotometric data for estimation gemcitabine hydrochloride $0.1 \mathrm{~N} \mathrm{HCl}(\mathrm{pH}-1.2)$}

\begin{tabular}{|c|c|c|}
\hline 1 & 5 & 0.159 \\
\hline 2 & 10 & 0.347 \\
\hline 3 & 15 & 0.570 \\
\hline 4 & 20 & 0.716 \\
\hline 5 & 25 & 0.860 \\
\hline 6 & 30 & 1.021 \\
\hline
\end{tabular}

\begin{tabular}{|c|c|c|c|}
\hline \multicolumn{4}{|c|}{ Table 4: Drug loading and drug Entrapment } \\
Efficiency.
\end{tabular}

Results are expressed as Mean + SD $(n=3)$

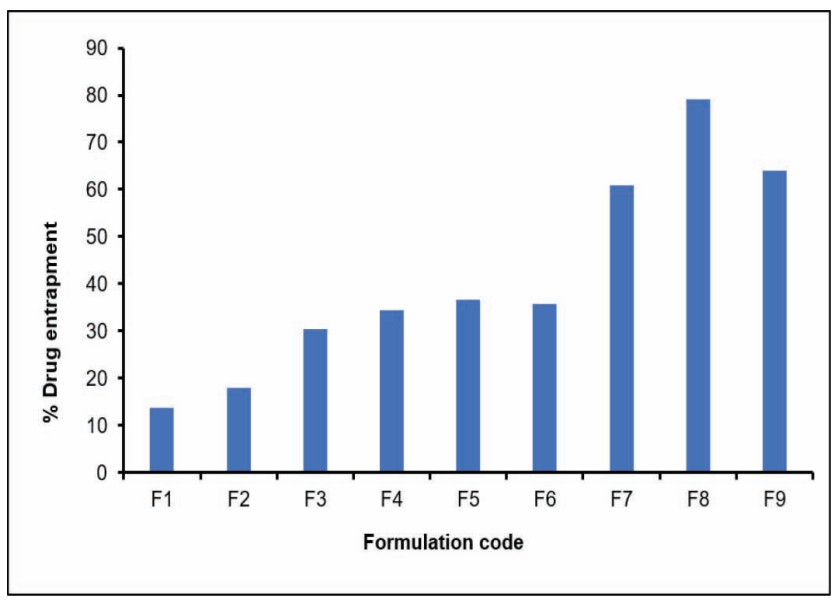

Figure 5: Histogram of drug entrapment. 


\begin{tabular}{|c|c|c|}
\hline \multicolumn{3}{|c|}{ Table 5: Particle Size Analysis. } \\
\hline SI. No & Formulation code & Mean Particle size $\mu \mathrm{m}( \pm$ SD) \\
\hline 1 & F1 & $625 \pm 16.28$ \\
\hline 2 & F2 & $684 \pm 23.36$ \\
\hline 3 & F3 & $620 \pm 15.38$ \\
\hline 4 & F4 & $570 \pm 21.72$ \\
\hline 5 & F5 & $508 \pm 19.28$ \\
\hline 6 & F6 & $544 \pm 15.26$ \\
\hline 7 & F7 & $490 \pm 22.39$ \\
\hline 8 & F8 & $428 \pm 12.20$ \\
\hline 9 & F9 & $402 \pm 10.18$ \\
\hline
\end{tabular}

Results are expressed as Mean \pm SD $(n=3)$

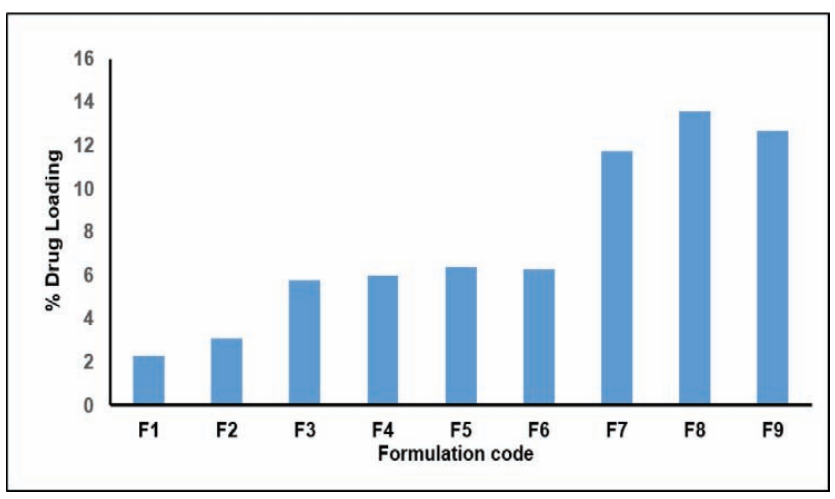

Figure 6: Histogram of drug loading.

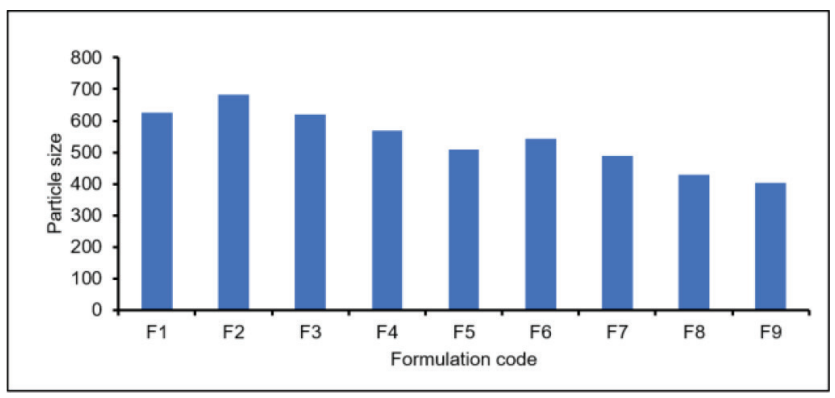

Figure 7: Mean Particle Size of Formulation F1 To F9. from $684 \pm 23.36$ to $402 \pm 10.18 \mu \mathrm{m}$, with increasing polymer as shown in Table 5 and the images of microspheres were taken using Optical microscope, as shown in Figure 7.

\section{Scanning Electron Microscopy (SEM)}

Scanning electron microscopy (FEI Quanta-200 MK2, Netherlands) was used to observe the surface morphology of microsphere, before and after dissolution, as shown in Figures 8A and 8B respectively.

\section{Micromeritic evaluation}

The micromeritic evaluation of the microspheres show satisfactory results, indicating a good flow property of the prepared microspheres.

\section{Swelling ability}

For increasing Calcium chloride concentration to $6 \%$, swelling of polymer decreased, as shown in Table 6 and Figure 9.

\section{In-vitro Drug Release Studies}

The drug release studies show that most of the formulationsshowed less than $10 \%$ releasein acid mediaso as to protect the drug from upper GI Tract and minimized side effects, as depicted in Figures 10, 11 and 12, respectively. Above $\mathrm{pH}-6.8$, ethyl cellulose shield began to dissolve and drug discharge increased gradually. The release rate kinetic data are fitted to the first order plot. Fickian diffusion suggests that drug is released by molecular diffusion and non-fickian diffusion suggest that relaxation release is the drug transport mechanism associated with stress - transition in hydrophilic glassy
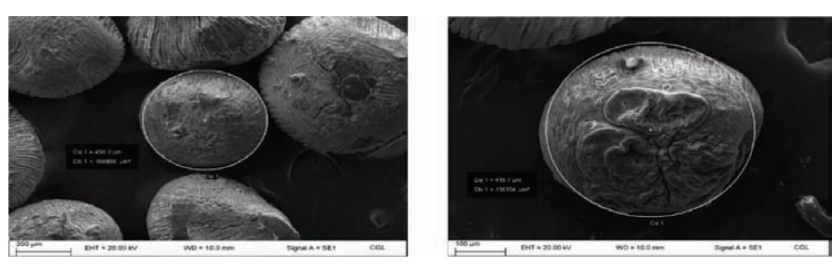

Figure 8: SEM images of Formulation 8 before and after dissolution respectively.

\begin{tabular}{|c|c|c|c|c|c|c|c|c|c|}
\hline \multicolumn{10}{|c|}{ Sable 6: Swellable Study of Microspheres. } \\
\hline \multicolumn{7}{|c|}{ Swelling Percentage of Formulation } \\
\hline Nature of Solvent & F1 & F2 & F3 & F4 & F5 & F6 & F7 & F8 & F9 \\
\hline Distilled Water & $0.71 \pm 0.23$ & $0.83 \pm 0.51$ & $1.02 \pm 0.41$ & $0.83 \pm 0.37$ & $0.89 \pm 0.2$ & $0.97 \pm 0.32$ & $0.98 \pm 0.30$ & $1.03 \pm 0.13$ & $1.16 \pm 0.34$ \\
\hline 0.1 N Hydrochloric acid & $0.62 \pm 0.24$ & $0.73 \pm 0.45$ & $0.72 \pm 0.42$ & $0.89 \pm 0.33$ & $0.85 \pm 0.21$ & $0.94 \pm 0.41$ & $0.88 \pm 0.38$ & $1.07 \pm 0.23$ & $1.12 \pm 0.42$ \\
\hline Phosphate Buffer & $0.28 \pm 0.04$ & $0.35 \pm 0.04$ & $0.63 \pm 0.05$ & $0.78 \pm 0.04$ & $0.45 \pm 0.04$ & $0.48 \pm 0.06$ & $0.67 \pm 0.03$ & $0.87 \pm 0.04$ & $0.77 \pm 0.02$ \\
\hline
\end{tabular}

Results are expressed as Mean + SD $(n=3)$ 


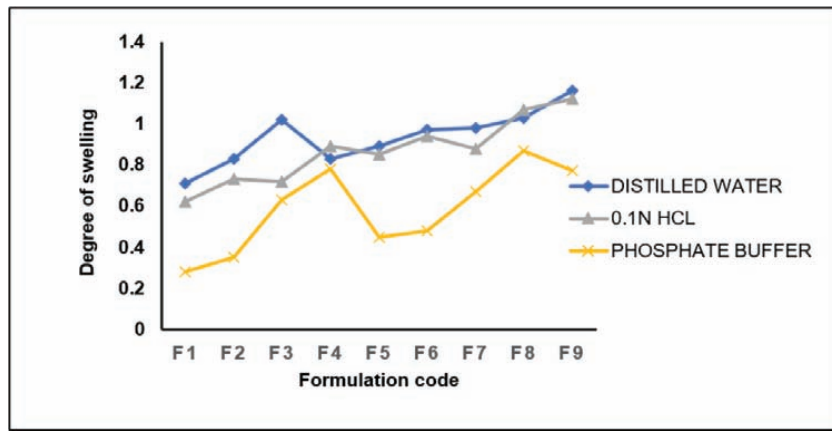

Figure 9: Swelling study of microsphere.

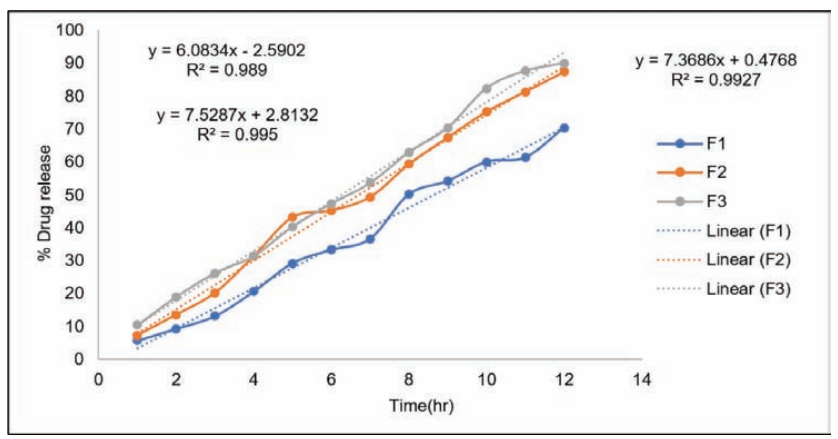

Figure 10: In-vitro drug release profile graph of Formulations $F 1, F 2$ and $F 3$.

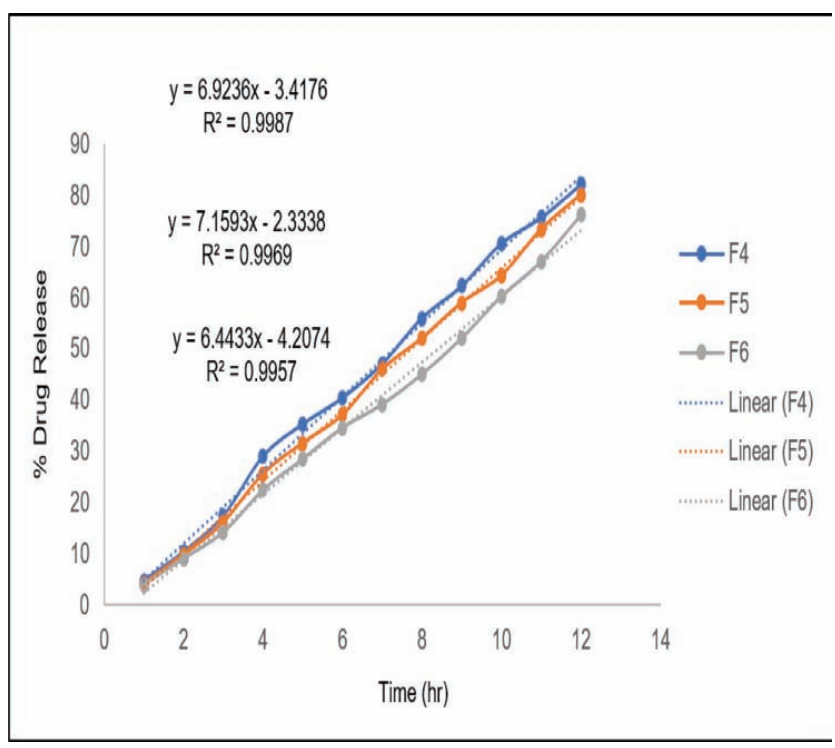

Figure 11: In-vitro drug release profile graph of Formulations F4, F5 and F6.

polymer, which swell in water or biological fluids. The 'n' values are characteristic of both case II and super case II transport, suggesting that more than one mechanism may be involved in release kinetic. High the value of ' $n$ ' shows polymer relaxation and swelling / erosion and drug is release in this fashion.

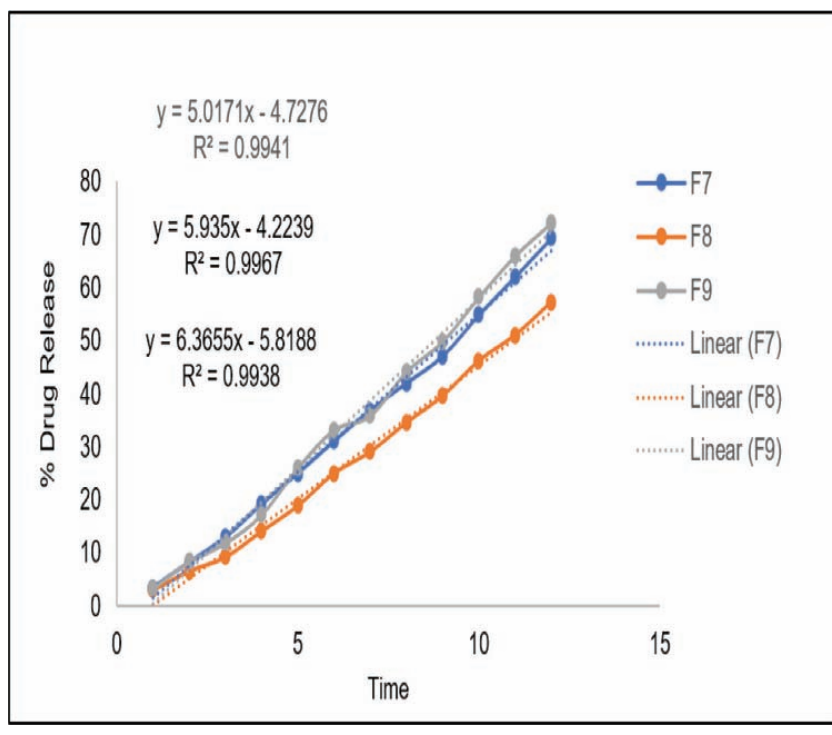

Figure 12: In-vitro drug release profile graph of Formulations F7, F8 and F9.

\section{CONCLUSION}

Microspheres have proven to be one of the best approaches in the field of novel drug delivery system. Prepared easily by ionotropic gelation method, drugs can be incorporated in them and this act as a great strategy in targeting drugs to various sites. Gemcitabine is used as a model drug, that is used treatment of pancreatic cancer. Microspheres are prepared using sodium alginate, ethyl cellulose and calcium chloride. Nine batches (F1, F2, F3, F4, F5, F6, F7, F8 and F9) were prepared and the augmented formulation, i.e. F8 was subjected to characterization studies like FT-IR, DSC, micromeritic studies, drug loading and drug entrapment, SEM, particle size analysis, swelling ability and in-vitro evaluation.

The results depicted a greater drug entrapment, with increase in polymer concentration and swelling ability of polymer decreases with increase in $\mathrm{CaCl}_{2}$ concentration. In-vitro drug release studies have shown only $10 \%$ release in the gastric environment and a greater drug release in the intestinal environment up to $12 \mathrm{hr}$. From this research, it was concluded that formulation of microspheres using suitable polymers can be an extremely effective strategy in treating a number of diseases, by offering a sustained release drug delivery system.

\section{ACKNOWLEDGEMENT}

The authors acknowledge their gratefulness to Calcutta Institute of Pharmaceutical Technology and Allied 
Health Sciences, West Bengal for imparting help in completion of the research work.

\section{CONFLICT OF INTEREST}

The authors declare that there are no conflicts of interest.

\section{ABBREVIATIONS}

GEM: Gemcitabine; HCl: Hydrochloric acid; DNA: Deoxyribonucleic acid; RNA: Ribonucleic acid; GI: Gastrointestinal; FT-IR: Fourier Transform Infra-Red Spectroscopy; KBr: Potassium Bromide; SEM: Scanning

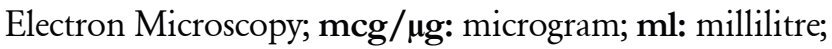
nm: nanometer; $\mu \mathrm{m}$ : micrometer; F1: Formulation-1; F2: Formulation-2; F3: Formulation-3; F4: Formulation-4; F5: Formulation-5; F6: Formulation-6; F7: Formulation-7; F8: Formulation-8; F9: Formulation-9; w/v: weight by volume; USP: United States Pharmacopoeia; rpm: rotations per minute.

\section{REFFERENCES}

1. Witjes JA, van der Heijden AG, Vriesema JL, Peters GJ, Laan A, Schalken JA. Intravesical gemcitabine: a phase 1 and pharmacokinetic study. Eur Urol. 2004 Feb;45(2):182-6. doi: 10.1016/j.eururo.2003.09.014, PMID 14734004.

2. Gontero P, Tizzani A. Intravesical gemcitabine: state of the art. Eur Urol Suppl. 2007;6(14):809-15. doi: 10.1016/j.eursup.2007.05.002.

3. Bergman AM, Pinedo HM, Peters GJ. Determinants of resistance to 2', 2'-difluorodeoxycytidine (gemcitabine). Drug Resist Updat. 2002 Feb 1;5(1):19-33. doi: 10.1016/s1368-7646(02)00002-x, PMID 12127861.

4. Xie J, Yuan J, Lu L. Gemcitabine fixed-dose rate infusion for the treatment of pancreatic carcinoma: a meta-analysis of randomized controlled trials. Diagn Pathol. 2014 Nov 25;9(1):214. doi: 10.1186/s13000-014-0214-8, PMID 25421173.

5. Derakhshandeh K, Fathi S. Role of chitosan nanoparticles in the oral absorption of gemcitabine. Int J Pharm. 2012 Nov 1;437(1-2):172-7. doi: 10.1016/j.jpharm.2012.08.008, PMID 22909993.

6. Shi P, Zuo Y, Zou Q, Shen J, Zhang L, Li Y, Morsi YS. Improved properties of incorporated chitosan film with ethyl cellulose microspheres for controlled release. Int J Pharm. 2009 Jun 22;375(1-2):67-74. doi: 10.1016/j. ijpharm.2009.04.016, PMID 19383531.
7. Shu XZ, Zhu KJ. Chitosan/gelatin microspheres prepared by modified emulsification and ionotropic gelation. J Microencapsul. 2001 Jan 1;18(2):237-45. doi: 10.1080/02652040010000415, PMID 11253940.

8. Kaur T, Kaur S, Kaur P. Development and validation of UV-spectrophotometric methods for determination of gemcitabine hydrochloride in bulk and polymeric nanoparticles. Int J Appl Pharm. 2017 Aug 22;9(5):60-5. doi: 10.22159/ ijap.2017v9i5.19726.

9. Acosta N, Sánchez E, Calderón L, Cordoba-Diaz M, Cordoba-Diaz D, Dom S, Heras Á. Physical stability studies of semi-solid formulations from natural compounds loaded with chitosan microspheres. Mar Drugs. $2015 \mathrm{Sep}$ 16;13(9):5901-19. doi: 10.3390/md13095901, PMID 26389926.

10. Rastogi R, Sultana Y, Aqil M, Ali A, Kumar S, Chuttani K, Mishra AK. Alginate microspheres of isoniazid for oral sustained drug delivery. Int J Pharm. 2007 Apr 4;334(1-2):71-7. doi: 10.1016/j.ijpharm.2006.10.024, PMID 17113732.

11. Sudhakar K, Rao KM, Sudhakar P, ChandraBabu A, Kumara Babu P, Subha MCS, Chowdoji Rao K. Development of $\mathrm{pH}$-sensitive polycaprolactone-based microspheres for in vitro release studies of triprolidine hydrochloride. Des Monomers Polym. 2014 Oct 3;17(7):617-23. doi: 10.1080/15685551.2014.907614.

12. Patel MA, AbouGhaly MH, Schryer-Praga JV, Chadwick K. The effect of ionotropic gelation residence time on alginate cross-linking and properties. Carbohydr Polym. 2017 Jan 2;155:362-71. doi: 10.1016/j. carbpol.2016.08.095, PMID 27702523.

13. Hu C, Lu W, Mata A, Nishinari K, Fang Y. lons-induced gelation of alginate: mechanisms and applications. Int J Biol Macromol. 2021 Apr 30;177:578-88. doi: 10.1016/j.jibiomac.2021.02.086, PMID 33617905.

14. Sahoo SK, Mallick AA, Barik BB, Senapati PC. Formulation and in vitro evaluation of Eudragit $\circledast$ microspheres of stavudine. Trop J Pharm Res. 2005;4(1):369-75. doi: 10.4314/tjpr.v4i1.14622.

15. Chen W, Palazzo A, Hennink WE, Kok RJ. Effect of particle size on drug loading and release kinetics of gefitinib-loaded PLGA microspheres. Mol Pharm. 2017 Feb 6;14(2):459-67. doi: 10.1021/acs.molpharmaceut.6b00896, PMID 27973854.

16. Hazra M, Dasgupta Mandal DD, Mandal T, Bhuniya S, Ghosh M. Designing polymeric microparticulate drug delivery system for hydrophobic drug quercetin. Saudi Pharm J. 2015 Sep 1;23(4):429-36. doi: 10.1016/j. jsps.2015.01.007, PMID 27134546.

17. Luo C, Yang Q, Lin X, Qi C, Li G. Preparation and drug release property of tanshinone IIA loaded chitosan-montmorillonite microspheres. Int J Biol Macromol. 2019 Mar 15;125:721-9. doi: 10.1016/j.ijbiomac.2018.12.072, PMID 30552926.

18. Zhang C, Jia R, Dong Y, Zhao L. Preparation and characterization of poly(3hydroxybutyrate-co-3-hydroxyhexanoate) microspheres for controlled release of buprofezin. Environ Sci Pollut Res Int. 2019 May;26(15):15518-26. doi: 10.1007/s11356-019-04869-w, PMID 30937744.

19. Pandey J, Shankar R, Kumar M, Shukla K, Kumari B. Development of nasal mucoadhesive microspheres of granisetron: A potential drug. Drug Res (Stuttg). 2020 Aug;70(8):367. doi: 10.1055/a-1193-4781, PMID 32559774. 
PICTORIAL ABSTRACT
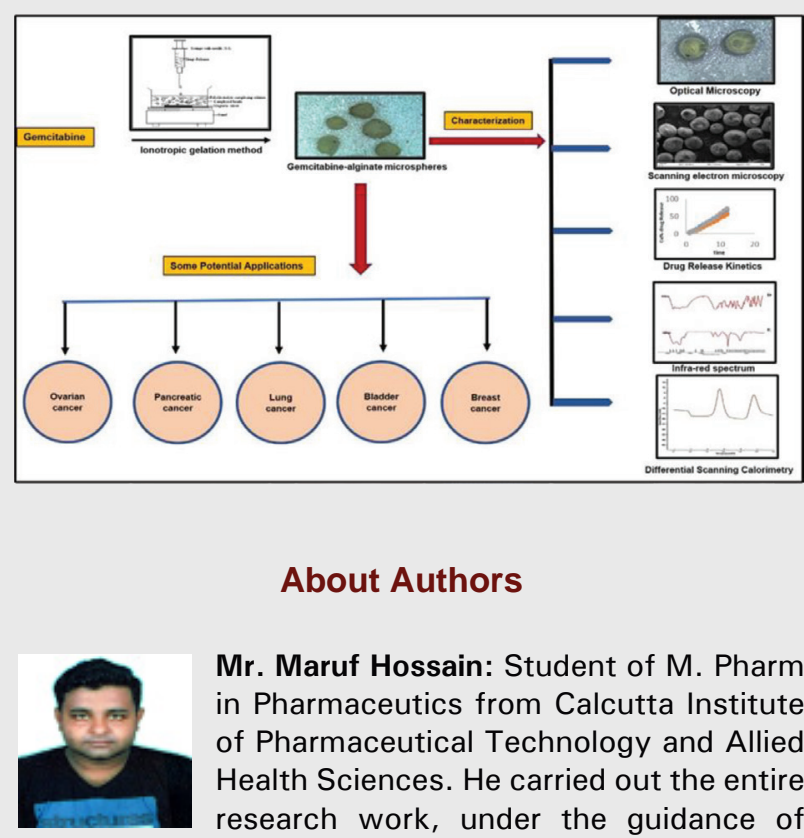

\section{About Authors}

Mr. Maruf Hossain: Student of M. Pharm in Pharmaceutics from Calcutta Institute of Pharmaceutical Technology and Allied Health Sciences. He carried out the entire research work, under the guidance of Mr. Soumya Ganguly and Mr. Hiranmoy Paria.

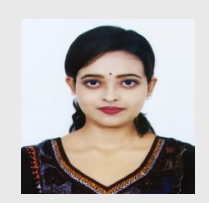

Mrs. Shayeri Chatterjee: Assistant Professor of Calcutta Institute of Pharmaceutical Technology and Allied Health Sciences, in Department of Pharmaceutics. She is the main author of this entire manuscript and the corresponding author. She is pursuing her Ph.D from Techno India University, Kolkata, West Bengal.

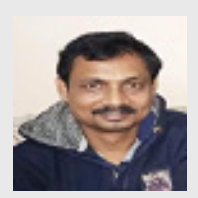

Mr. Hiranmoy Paria: Assistant Professor of Calcutta Institute of Pharmaceutical Technology and Allied Health Sciences, in Department of Pharmaceutics. He had allotted the research title to the scholar and supervised him in the research work.

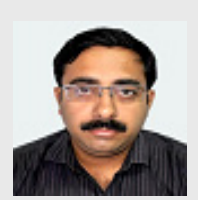

Mr. Soumya Ganguly: Assistant Professor of Calcutta Institute of Pharmaceutical Technology and Allied Health Sciences, in Department of Pharmaceutics. He guided the scholar, procured the drug and supervised the entire research work. $\mathrm{He}$ is carrying out his Ph.D research work from Jadavpur University, Kolkata, West Bengal.

\section{SUMMARY}

Gemcitabine loaded microspheres have been prepared in this research work, by using sodium alginate, calcium chloride and ethyl cellulose. The method employed in the preparation technique is ionotropic gelation. Gemcitabine is transported into the cell, phosphorylated, and incorporated into DNA and RNA, causing impediment of growth activity and it also moderates apoptosis. In order to show the pharmacological activity in subjects, it has to be phosphorylated into its active metabolite, which are gemcitabine triphosphate and diphosphate, occurring by the action of deoxycytidine kinase in the body. These active metabolites get incorporated into the DNA strand and inhibit the DNA synthesis thereby inhibiting cell growth. Hence it can be well established that the formulation is effective against a variety of carcinomas. The prepared microspheres have been subjected to numerous evaluation tests and satisfactory results have been obtained in all the tests. Moreover, it is observed that greater drug entrapment occurs, with increase in polymer concentration and swelling ability of polymer decreases with increase in $\mathrm{CaCl}_{2}$ concentration. In-vitro drug release studies have exhibited that only $10 \%$ release in the gastric environment occurs and a greater percentage of drug releases in the intestinal environment up to 12 hours. Thus it can be concluded and summarized that this formulation can be fabricated using suitable polymers, that would be an effective strategy in treating tumors and carcinomas, by retarding the drug release.

Cite this article: Hossain M, Chatterjee S, Paria H, Ganguly S. Fabrication and Evaluation of Gemcitabine-loaded Alginate Microspheres: A Potential Approach for Treatment of Various Carcinomas. Indian $\mathrm{J}$ of Pharmaceutical Education and Research. 2022;56(1):86-93. 